\title{
Observações sobre o comportamento de nidificação de três espécies de Podocnemis Wagler (Testudinata, Pelomedusidae) no Baixo Rio Branco, Roraima, Brasil
}

\author{
Sebastião Pereira do Nascimento ${ }^{1}$
}

\begin{abstract}
Observation on nidification behavior of three species of Podocnemis Wagler (Testudinata, Pelomedusidae) in the Baixo Rio Branco, Roraima, Brazil. Some aspects on nidification behavior of three species of turtles [Podocnemis unifilis (Troschel, 1848), Podocnemis sextuberculata (Cornália, 1849) and Podocnemis expansa (Schweigger, 1812)] in the northern Brazilian Amazonia are reported. The three species showed similar nidification activities.
\end{abstract}

KEY WORDS. Turtle, behavior, nidification, synchronization

O comportamento de nidificação das espécies de quelônios do gênero Podocnemis Wagler, 1830, em geral, está intimamente associado ao ciclo hidrológico (CARR \& GIOVANNOLI 1957). Durante o período de cheia, as espécies ocupam lugares isolados ao longo dos rios como lagos marginais, pequenos igarapés e áreas alagadas. A migração dos indivíduos adultos (machos e fêmeas) para reprodução, coincide com o início da vazante e parece marcar o estímulo destes animais no sentido de se deslocarem até o local de nidificação (ALHO \& PÁDUA 1982a,b). Este grau de sincronia entre o rio e as tartarugas, influência decisivamente na vida reprodutiva das populações, controlando e determinando os vários tipos de comportamentos característicos de cada espécie. Alguns desses padrões de comportamento são reconhecidamente próprios das espécies de Podocnemis e foram descritos por autores como CARR \& GIOVANNOLI(1957), VANZOLINI (1967), OJASTI (1967), AlHO \& PÁduA (1982c) para P. expansa (Schweigger, 1812) na região do rio Trombetas, Estado do Pará, rio Madeira, Estado de Rondônia e rio Orinoco, Venezuela.

Para o Estado de Roraima, situado no extremo norte da Amazônia, os estudos sobre populações de quelônios são praticamente inexistentes e impossibilitam qualquer tentativa organizada de manejo sustentado das espécies tradicionalmente utilizadas para consumo humano. No intuito de ampliar as informações básicas sobre este grupo, estas observações tem por objetivo relatar o comportamento de nidificação das espécies Podocnemis expansa, $P$. unifilis (Troschel, 1848) e $P$. sextuberculata (Cornália, 1849), que ocorrem na região do Baixo Rio Branco, Estado de Roraima, baseado em observações de campo realizadas entre os anos de 1997 a 1999, nas praias de desovas (tabuleiros) de Santa Fé ao longo da calha sul do rio Branco, onde está localizada a área "assegurada" pelo IBAMA/RR, para permanência e reprodução natural daquelas populações de quelônios.

1) Setor de Zoologia, Museu Integrado de Roraima. Avenida Brigadeiro Eduardo Gomes, Parque Anauá, 69305-010 Boa Vista, Roraima, Brasil. 


\section{Podocnemis unifilis (Troschel, 1848)}

Esta espécie inicia sua atividade de nidificação na região do Baixo Rio Branco entre dezembro e janeiro, variando em função do regime de vazante do rio. Este processo é iniciado com a migração desses animais das águas mais profundas, para as águas mais rasas, seguindo-se a agregação da população nas proximidades do sítio de nidificação. Nesta fase (que pode durar de 10 a 20 dias), o animal vez por outra, vêm a superfície, pondo a cabeça fora d'água, numa seqüência de intervalo sincronizado. Após essa etapa, as fêmeas dirigem-se à praia no intuito de exporem-se ao sol, principalmente nas horas mais quente do dia, no fenômeno conhecido popularmente como "assoalhamento". Em seguida, é realizada (à noite) uma caminhada de "vistoria" pela praia e a escolha do local de oviposição que, em geral, é feita entre os meses de janeiro e fevereiro, podendo se estender até março, dependendo das condições hidrológicas do rio. A postura é precedida pela escavação da cova, que varia de 20 a $30 \mathrm{~cm}$ de profundidade, seguido do enchimento e compactação da mesma e, finalizada com retorno das fêmeas à água. Essa espécie deposita de 8 a 26 ovos de formato alongado, dispostos em camadas dentro da câmara de postura, o período de incubação varia entre 45-55 dias. Segundo Molina \& Rocha (1996), é possível que essa espécie realize mais de uma postura por estação reprodutiva.

As observações realizada no tabuleiro da Santa Fé (Baixo Rio Branco), entre os meses de novembro e dezembro de 1997, janeiro e março de 1998 e fevereiro e abril de 1999 , indicam que a $P$. unifilis apresenta pouco grau de sociabilidade e não é muito exigente, quanto a escolha do seu local de desova. Ao contrário de $P$. expansa, pode ovipositar em ambientes mais "rústicos" como por exemplo, em pequenos bancos de areia, em locais isolados com vegetação ou até mesmo nos "barrancos" altos das praias. De acordo com as observações in loco é possível conjecturar que essa falta de preferência pelo local de desova, esteja ligada intimamente a um grande vigor de adaptabilidade dessa espécie na região, além de uma possível forma de estratégia para proteção da ninhada.

\section{Podocnemis sextuberculata (Cornália, 1849)}

A atividade de nidificação do $P$. sextuberculata está relacionada com o início da vazante do rio Branco, a partir do mês de setembro, quando começam aparecer os primeiros bancos de areias, onde pouco mais tarde, as fêmeas executam suas posturas. Essa atividade começa com o processo migratório da população, procedente dos lagos marginais ou áreas alagadas em direção as águas mais rasas, variando em tempo e função do regime de vazante do rio. De acordo com os dados levantados estes quelônios apresentam uma série de padrões de comportamentos, semelhantes aos observados em $P$. unifilis e $P$. expansa. Este conjunto de comportamento, inicia-se com a agregação dos animais nas proximidades do tabuleiro de desova, onde permanecem por 10 a 20 dias, executando movimento sincronizado de exposição das suas cabeças fora d'água, sempre orientadas em direção ao sítio de nidificação. No início de outubro, acontece o "assoalhamento", tipo de comportamento social, onde os animais sobem à praia, para se expor ao sol, sempre nos horários mais quentes do dia.

As etapas seguintes acontecem geralmente à noite, com a caminhada de "vistoria" à praia para a escolha do local de desova e, posteriormente a escavação da 
cova que varia de 17 a $26 \mathrm{~cm}$ de profundidade, a oviposição, o aterramento e compactação da cova e finalmente o retorno das fêmeas à água. Sendo que essa série de comportamento, pode ocorrer do final de outubro, até o final de novembro, dependendo da situação climática-hidrológica da região que, por sua vez, influencia na dinâmica do rio e no comportamento desses quelônios. MOLINA \& ROCHA (1996) admitem que essa espécie possa realizar mais de uma postura por estação reprodutiva, depositando de 8 a 26 ovos de formato alongado, dispostos em camadas dentro da câmara de postura. O tempo de incubação varia entre 40 e 60 dias, dependendo das condições de insolação direta no ninho. Todos estes valores foram observados e constatados nos tabuleiros de Santa Fé (Baixo Rio Branco), nos períodos de setembro e novembro de 1997, outubro e novembro de 1998 e setembro e outubro de 1999.

De modo geral $P$. sextuberculata é semelhante a $P$. unifilis quanto a sua rusticidade na escolha do local para sua oviposição, essa espécie costuma desovar tanto em praias mais baixas quanto altas e/ou em áreas isoladas com vegetação. Sendo estes ambientes encontrados sem muita dificuldade na calha sul do rio Branco. Outra semelhança bastante comum entre as duas espécies, está relacionado ao seu comportamento pouco social, embora, ocasionalmente, possam construir seus ninhos próximos uns dos outros, na maioria das vezes preferem fazer isso isoladamente.

\section{Podocnemis expansa (Schweigger, 1812)}

A migração de $P$. expansa em busca de áreas favoráveis à sua desova está sujeita às condições pluviométricas da região, pois acabam determinando uma maior ou menor vazante e, conseqüentemente, o abaixamento do nível das águas dos rios e o afloramento dos bancos de areia, denominados de tabuleiros (ALFINITO 1975). No baixo rio Branco, o período de desova da $P$. expansa vai de novembro a dezembro, podendo chegar até meados de janeiro, o que coincide com a fase de maior vazante do rio Branco. Contudo, o processo de nidificação dessa espécie, tem início logo na primeira fase do abaixamento das águas (a partir de setembro), com a atividade migratória da população, procedente dos lagos marginais ou ainda (segundo observações pessoais), uma possível saída do rio Negro, Estado do Amazonas, em direção as áreas de desovas no rio Branco. Após a migração, ocorre a agregação da população próximo aos tabuleiros, onde, de vez em quando, algumas fêmeas se expõem colocando a cabeça fora d'água, numa seqüência cadenciada estereotipada (ALHO et al. 1979; ALHO \& PÁDUA 1982a). No final de outubro, acontece a subida à praia para exposição ao sol (assoalhamento), geralmente nos horários de maior pico do sol. Após essa performance, vem as atividades noturnas. Primeiro, com a caminhada pela praia para "vistoria" e escolha do local de desova; em seguida a escavação da cova que varia de 50 e $60 \mathrm{~cm}$ de profundidade, a oviposição, o aterramento e compactação do ninho e o retorno das fêmeas à água, as quais permanecem durante todo o período de incubação ( 45 a 50 dias), em locais próximos aos tabuleiros, possivelmente, até o início das chuvas na região (abril/ maio). A fêmea deposita em média 120 ovos de formato alongado, dispostos em camadas dentro da câmara de postura, podendo realizar mais de uma desova por estação reprodutiva, conforme atestam MOLINA \& ROCHA (1996). De acordo com observações nas praias de Santa Fé (Baixo Rio Branco), durante os períodos de setembro e dezembro de 1997, janeiro e outubro de 1998 e fevereiro e março de 
1999, a $P$. expansa apresenta um tipo de comportamento social, sendo extremamente sensível às perturbações antrópicas e muito seletiva, quanto à procura de lugares ideais para sua reprodução, preferindo sempre praias grandes e altas.

A despeito do comentários de que essa espécie desova anos seguidos numa mesma praia, dentro das minhas observações, não foi possível detectar este fato. Entretanto, OJASTI (1967), afirma que na calha do rio Orinoco (Venezuela), essa espécie desova anos após ano sempre nas mesmas praias.

\section{Consideraçōes finais}

De maneira geral as três espécies de Podocnemis apresentam uma série de padrões de comportamento semelhantes entre si. Por outro lado, são também muito semelhantes quanto aos fatores ambientais naturais, no caso do regime de vazante do rio, que funcionam como um mecanismo que desencadeia o comportamento de migração dos lagos e igarapés para os locais de oviposição ou de início do ritual de nidificação com a estabilização das águas dentro dos seus níveis mais baixos (PÁDUA \& ALHO 1984). Contudo, as poucas observações de campo realizadas e a inexistência de outros dados, limitam o aprofundamento na discussão acerca do processo de nidificação das espécies aqui comentadas. Contudo, os dados obtidos sugerem a necessidade de estudos que possam compreender de forma mais ampla, a estratégia reprodutiva e a dinâmica dessas populações na região do Baixo Rio Branco, bem como, gerar informações que possam contribuir na elaboração de programas, que visam garantir a livre reprodução e a permanência dessas espécies em suas áreas de ocorrência na Amazônia.

\section{REFERÊNCIAS BIBLIOGRÁFICAS}

Alfinito, J. 1975. A Preservação da Tartaruga Amazônica. Brasil Floretal, Brasília, 6 (21): 20-23.

ALHo, C.J.R.; A.G. CARVALho \& L.F.M.A. PÁduA. 1979. Ecologia da tartaruga da Amazônia e avaliação de seu manejo na Reserva Biológica do Rio Trombetas. Brasil Florestal, Brasília, 38: 29-47.

ALHo, C.J.R. \& L.F.M. PÁDUA. 1982a. Sicronia entre o regime de vazante do rio e o comportamento de nidificação de Podocnemis expansa (Testudinata: Pelomedusidae). Acta Amazônica 12 (2): 323-326.

- 1982b. Early of pen-reared Amazon turtle Podocnemis expansa (Testudinata, Pelumedusidae). Rev. Brasil. Biol. 42: 641-646.

- 1982c. Reproductive parameters and nesting behavior of the Amazon turtle Podocnemis expansa (Testudunata: Pelomedusidae) in Brazil. Canadian Jour. Zool. 50: 97-103.

Carr, A. \& L. Giovannoli. 1957. The ecology and migrations of sea turtles. II. Results of field work in Costa Rica, 1955. Amer. Mus. Novit. 1835: 1-32.

MolinA, F.B. \& M.B. RochA. 1996. Identificação, caracterização e distribuição dos Quelônios da Amazônia Brasileira. In: Anais XI Encontro Quelônios da Amazônia. Belém, Centro Nacional dos Quelônios da Amazônia, CENAQUA/IBAMA, p. 1-25.

OjAST1, J. 1967. Consideraciones sobre la ecologia y conservacion de la tortuga "Podocnemis expansa" (Chelonia: Pelomedusidae). Atas Simpósio Biota Amazônica, vol. 7, p. 201-206.

PÁduA, L.F.M. \& C.J.R. AlHo. 1984. Avaliação do Comportamento de Nidificação em Podocnemis expansa (Testudinata, Pelomedusidae) durante cinco anos em áreas de proteção. Reserva Biológica do Rio Trombetas, Pará. Brasil Florestal, Brasília, 59:59-61.

VANzolini, P.E. 1967. Notes on the nesting behavior of Podocnemis expansa in the Amazon valley (Testudinata, Pelomedusidae). Papéis Avulsos Zool., São Paulo, 20: 191-215.

Recebido em 10.VIII.2000; aceito em 21.II.2002. 